\title{
THE MULTIDIMENSIONAL REVERSE HARDY INEQUALITIES
}

\section{A. Gogatishvili and R. Ch. MustafayeV}

Abstract. In this paper we characterize the validity of the multidimensional reverse Hardy inequalities

$$
\|g w\|_{L_{p}\left(\mathbb{R}^{n}\right)} \leqslant C\left\|v(t) \int_{C_{B(0, t)}} g(y) d y\right\|_{L_{q}(0,+\infty)}
$$

and

$$
\|g w\|_{L_{p}\left(\mathbb{R}^{n}\right)} \leqslant C\left\|v(t) \int_{B(0, t)} g(y) d y\right\|_{L_{q}(0,+\infty)}
$$

for non-negative measurable functions on $\mathbb{R}^{n}$, where $B(0, t)$ is the closed ball in $\mathbb{R}^{n}$ centered at zero with radius $t,{ }^{\complement} B(0, t)=\mathbb{R}^{n} \backslash B(0, t), 0<p \leqslant 1,0<q \leqslant+\infty, w$ and $v$ are weight functions on $\mathbb{R}^{n}$ and $(0,+\infty)$, respectively. Obtained conditions are the natural extensions of one-dimensional conditions.

Mathematics subject classification (2010): 26D10, 26D15, 46E30.

Keywords and phrases: Multidimensional Hardy operator, Hardy inequality, reverse Hardy inequality, discretization.

\section{REFERENCES}

[1] P. Drábek, H.P. Heinig And A.Kufner, Higher-dimensional Hardy inequality, In: General Inequalities 7 (Oberwolfach, 1995), Internat. Ser. Numer. Math. 123 (1997), Birkhäuser, Basel, 1997, 3-16.

[2] W. D. Evans, A. Gogatishvili And B. Opic, The reverse Hardy inequality with measures, Math. Ineq. and Appl., bf 11 (2008), 43-74.

[3] A. Gogatishvili And L. Pick, Discretization and anti-discretization of rearrangement-invariant norms, Publ. Mat., 47 (2003), 311-358.

[4] K.-G. Grosse-Erdmann, The Blocking Technique. Weighted Mean Operators and Hardy's Inequality, Lect. Notes Math. 1679, Springer, Berlin, 1998.

[5] A. Kufner, L. Maligranda And L. E. Persson, The Hardy Inequality. About its History and Some Related Results, Vydavatelský servis Publishing House, Pilsen, 2007.

[6] A. Kufner And L.-E. Persson, Weighted inequalities of Hardy type, World Scientific Publishing Co, Singapore, 2003.

[7] L. LeINDLER, Inequalities of Hardy and Littlewood type, Acta Sci. Math. (Szeged), bf 2 (1976), $117-123$.

[8] L. LeINDLER, On the converses of inequalities of Hardy and Littlewood, Acta Sci. Math. (Szeged), 58 (1993), 191-196.

[9] B. OpIC And A. Kufner, Hardy-type inequalities, Pitman Research Notes in Mathematics Series, 219, Longman Scientific \& Technical, Harlow, 1990. 